\title{
O ESTÍMULO AO EMPREENDEDORISMO NOS CURSOS DE QUÍMICA: FORMANDO QUÍMICOS EMPREENDEDORES
}

\author{
Maria H. Araújo e Rochel M. Lago* \\ Departamento de Química, ICEx, Universidade Federal de Minas Gerais, CP 702, 31270-901 Belo Horizonte - MG \\ Luiz C. A. Oliveira \\ Departamento de Química, Universidade Federal de Lavras, 37200-000 Lavras - MG \\ Paulo R. M. Cabral \\ Instituto Inovação, Rua Cláudio Manuel, 237, 31140-100 Belo Horizonte - MG \\ Lin Chih Cheng \\ Departamento de Engenharia de Produção, Universidade Federal de Minas Gerais, 31270-901 Belo Horizonte - MG \\ Louis Jacques Filion \\ HEC, 3000 Côte Sainte-Catherine, Montréal, Quebec, H3T 2A7, Canadá
}

\begin{abstract}
STIMULATING ENTREPRENEURSHIP IN CHEMISTRY COURSES: THE FORMATION OF ENTREPRENEURIAL CHEMISTS. The Universities, in Brazil and all over the world are currently going through a "second revolution" in which the socio-economical development is incorporated as part of their mission and science and knowledge play a key role for the development of the society. In this context, this article is directed towards the importance of entrepreneurship and the formation of technological entrepreneurs in the area of chemistry, with special attention to the teaching of entrepreneurship in the chemistry courses and its effect on students, universities and the job possibilities. This article also presents a short discussion on a basic entrepreneurship course for chemists and some suggestions of reading on entrepreneurship to those interested in get started in this area. What is presented here about entrepreneurship in chemistry can be applied to any other area of science and technology.
\end{abstract}

Keywords: entrepreneurship; education; chemistry.

\section{INTRODUÇÃO}

As Universidades, do Brasil e do mundo, estão atualmente passando por uma "segunda revolução" onde o desenvolvimento social e econômico é incorporado como parte da missão da universidade. A primeira revolução foi feita quando, além do ensino, a pesquisa passou a ser parte da universidade. Agora, a Universidade integra o desenvolvimento econômico e social como uma função adicional e tem sido chamada "Universidade Empreendedora" (Esquema 1).

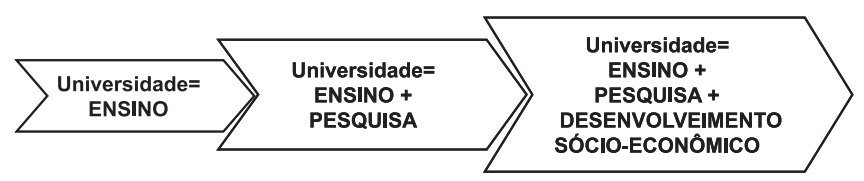

Esquema 1

Dentro deste modelo de Universidade Empreendedora, a ciência e a "capitalização do conhecimento" emergem como um motor alternativo para o crescimento econômico. Embora atividades diferentes de pesquisa e ensino, especialmente atividades de natureza comercial, sejam consideradas irrelevantes ou, em muitos casos, vulgares, esta situação tem mudado rapidamente nos últimos anos, como reconhecem Etzkowitz et al. ${ }^{1}$ no artigo intitulado "The future of the university and the university of the future: evolution of ivory tower to entrepreneurial paradigm" (O futuro da Universidade e a Universidade do futuro: evolução da torre de marfim ao paradigma empreendedor). Atividades empreendedoras têm ganhado progressivamente o respeito e a legitimidade aos olhos de autoridades políticas e acadêmicas. Durante as duas décadas pas-

*e-mail: rochel@ufmg.br sadas, um número cada vez maior de cientistas acadêmicos e estudantes têm-se envolvido com o processo empreendedor para iniciar uma empresa, escrevendo planos de negócio, levantando financiamentos, selecionando pessoal, etc ${ }^{2-4}$.

No Brasil esta tendência é bastante clara também, o que pode ser notado pela criação de centros de empreendedorismo, incubadoras, parques tecnológicos, "spin-offs" acadêmicos (empresas nascentes geradas a partir de resultados de pesquisas desenvolvidas na Universidade), proteção da propriedade intelectual e transferência de tecnologia para o setor privado ${ }^{5-7}$. Observa-se um apoio crescente a estas iniciativas por parte das agências de fomento à pesquisa, tais como CNPq, FINEP, Fundações Estaduais de Pesquisa e um incentivo dos governos Federal, Estaduais e Municipais. Todas estas iniciativas devem ganhar mais suporte com a promulgação da Lei da Inovação Tecnológica, que foi recentemente aprovada no Congresso Nacional. Em dois artigos recentes, Andrade e colaboradores ${ }^{8,9}$ sugerem seis eixos Mobilizadores em Química, entre os quais figuram: "o estímulo ao empreendedorismo" e "a interação pró-ativa de acadêmicos com a atividade econômica", que ilustram muito bem esta tendência atual.

Neste contexto, a Química tem um papel essencial, sendo uma ciência central onde aplicações tecnológicas têm grande repercussão no desenvolvimento de áreas tais como a biotecnologia, a ciência dos materiais, as nanociências, a área ambiental, entre outras. A formação de profissionais que sejam capazes de transformar o conhecimento químico gerando tecnologias, processos, riquezas e empregos é de grande relevância.

Uma pergunta que se coloca aqui é: durante a vida acadêmica de nossos alunos existe qualquer conteúdo, incentivo ou forma de apoio que possa despertar o lado empreendedor nos estudantes? Os profissionais na área de Química e ciências em geral estão sendo formados para buscar um emprego no setor público ou privado, e 
muitos, sem alternativa, ingressam nos programas de Pós-graduação para realização do mestrado ou doutorado. Não deveríamos formar químicos mais pró-ativos, aptos a serem protagonistas no processo de desenvolvimento industrial nacional? Químicos capazes de identificar oportunidades de negócios e transformar conhecimento científico na geração de tecnologia, agregando valor, criando empregos e divisas? A formação de empreendedores, especialmente de negócios de base tecnológica é fundamental para o desenvolvimento sustentável em uma economia altamente competitiva e globalizada que temos hoje. Dentro deste contexto, as Universidades têm papel fundamental como formadora de profissionais e formadora de opinião.

\section{O QUE É EMPREENDEDORISMO?}

Palavra de origem francesa, "entreprende" ou "entrepreneur" literalmente significa "o intermediário", aquele que está no centro ou no meio. Originalmente, estava relacionado com a atividade de um intermediário, aquele que fica "entre" o fornecedor e o mercado e que facilita o processo de troca ${ }^{10}$. Neste sentido, o empreendedor é a pessoa que "faz acontecer". A figura do empreendedor pode ser vista como a criadora: aquele que transforma uma troca em potencial em uma troca real, aquele sem o qual a transação poderia nunca ocorrer. Extrapolando o caso onde a demanda (ou seja a necessidade de um produto) existe mas o fornecimento não, o empreendedor pode criar o fornecimento e efetuar a troca. No caso de tecnologias completamente novas, o empreendedor pode mesmo ter que criar um mercado que ainda não existe.

O empreendedorismo hoje é uma ciência com mais de 80 anos, que tem crescido muito rapidamente no mundo inteiro e desenvolvido uma forte base empírica e teórica. Vários periódicos científicos $(43 \text { periódicos com referagem })^{11}$ são dedicados à ciência do empreendedorismo. Dentre as muitas definições encontradas na literatura, uma que parece englobar os diferentes aspectos do empreendedorismo é "Empreendedorismo é o processo de fazer algo novo (criação) elou algo diferente (inovação) com o propósito de criar riqueza para o indivíduo e agregar valor para a sociedade ${ }^{\prime 12}$.

\section{POR QUE O EMPREENDEDORISMO É IMPORTANTE PARA A SOCIEDADE?}

A importância das micro, pequenas e médias empresas na economia de qualquer país é inegável. Estas empresas são responsáveis pela geração de grande parte dos empregos formais e informais, de uma fração importante das exportações e do PIB de um país. No Brasil, as micro e pequenas empresas são responsáveis por $57,3 \%$ dos empregos formais e respondem por aproximadamente $2,2 \%$ das exportações e $20 \%$ do PIB $^{13}$.

O empreendedorismo é fator determinante para a geração dessas empresas e para impulsionar o crescimento econômico sustentável, necessários em países emergentes. A formação de novas empresas gera empregos, distribui renda e cria oportunidades para toda a sociedade. Empreendedores tornam-se exemplos, assumindo riscos ao transformar suas indústrias e estimulando outras pessoas através de suas conquistas e determinação. Portanto, a promoção de um modelo de desenvolvimento baseado no estímulo à atividade empreendedora é a forma mais eficiente de impactar a economia e a estrutura das sociedades ${ }^{14}$.

Talvez um aspecto especialmente importante para nós da comunidade acadêmica seja o empreendedorismo tecnológico, levando à criação de empresas inovadoras, que tem sido o motor propulsor por trás das economias mais fortes do mundo $^{14}$ (Esquema 2).

Os benefícios que este tipo de empreendedorismo pode trazer

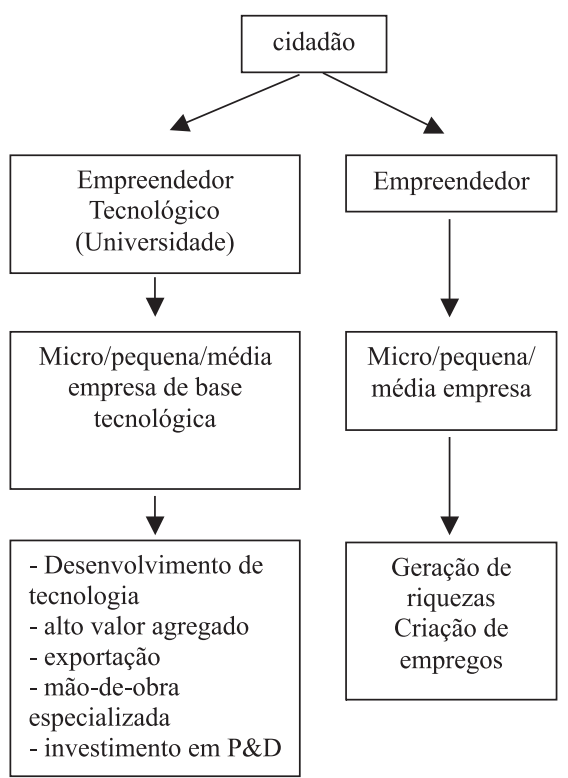

Esquema 2

ao Brasil são imensos. Nos EUA, empresas inovadoras, recém criadas, foram responsáveis por $90 \%$ dos empregos nos últimos vinte $a_{\text {anos }}{ }^{14}$. O perfil dos negócios brasileiros é em sua maioria baseado em empresas que atuam com produtos e serviços tradicionais. Estas empresas não têm nenhum ou somente um pequeno potencial de expansão de mercado ou impacto na criação de empregos e na conquista de consumidores distantes ou localizados fora do país. Em países mais ricos é significativamente maior a proporção de empreendimentos de alta expansão tecnológica e de mercado, o que leva a um impacto muito maior na geração de empregos e no comércio internacional. Neste sentido, o apoio ao empreendedorismo tecnológico é de fundamental importância no Brasil.

\section{COMO PROMOVER O EMPREENDEDORISMO EM NOSSA SOCIEDADE?}

Algumas das principais barreiras para a propagação do empreendedorismo no Brasil foram identificadas no relatório GEM $^{15}$. O GEM (“Global Entrepreneurship Monitor”) é um relatório internacional bastante abrangente sobre a atividade empreendedora em um grande número de países do mundo, que é preparado em conjunto pela "London Business School", "Babson College", "Kauffman Center for Entrepreneurial Leadership" e, no Brasil, pelo IBQP (Instituto Brasileiro da Qualidade e Produtividade no Paraná), SEBRAE e IEL.

Algumas destas barreiras pertencentes à macro-esfera são o alto custo e a dificuldade de acesso ao capital; políticas governamentais que impõem alta carga tributária, elevados encargos trabalhistas e excesso burocrático-regulatório. No entanto, no nível da micro-esfera alguns pontos importantes onde a comunidade acadêmica pode atuar mais diretamente são:

(i) um sistema educacional insuficiente tanto para preparação de mão-de-obra quanto para desenvolvimento do espírito e das habilidades do empreendedorismo entre os estudantes;

(ii) a forte cultura de buscar um emprego na esfera pública e nas grandes empresas privadas;

(iii) a ausência de programas de apoio ao empreendedorismo e,

(iv) fraca integração entre as iniciativas empreendedoras existentes e informações sobre o tema.

Assim, a proposição do estudo GEM Brasil 2003 foi que a edu- 
cação deve ter um destaque especial, merecendo diversas menções, que vão desde a "melhoria geral no sistema de ensino", até a "introdução de disciplinas e conteúdos específicos de empreendedorismo, principalmente na educação secundária e superior".

\section{EMPREENDEDORISMO E EDUCAÇÃO}

O ensino superior e também os cursos profissionalizantes de ensino médio em nosso país são orientados quase que exclusivamente para a formação do "candidato a emprego", um posto de trabalho, onde geralmente se exige pouco ou nada em termos de iniciativa própria e criatividade ${ }^{14}$. A Universidade é considerada fundamental neste processo porque ela é fonte multiplicadora do saber e forte formadora de opinião (1637 universidades, aproximadamente 3 milhões de estudantes e 12155 cursos presenciais). Sem dúvida, o Brasil ainda tem a necessidade de formação de mão-deobra especializada para atender à demanda, tanto do setor público quanto, especialmente, do setor privado ${ }^{16}$. No entanto, o ensino baseado apenas na formação de mão-de-obra é um modelo já ultrapassado, onde a formação de empregados para o setor público/privado já deixa de ser essencial no contexto moderno. Mesmo nos cursos de administração, o currículo ainda é dirigido para a formação de gerentes de grandes empresas, privadas ou públicas, sendo que a pequena e média empresas e mesmo o terceiro setor são tratados como secundários ${ }^{15}$.

O estímulo ao empreendedorismo e ao espírito empreendedor aos estudantes certamente resultarão na formação de um profissional diferenciado, seja como empreendedor seja como empregado. Como empreendedores, estes profissionais poderão criar empreendimentos inovadores e proporcionar oportunidades de trabalho e realização profissional para outros trabalhadores ${ }^{15}$. Como empregados "intra-empreendedores", poderão exercer muito mais sua criatividade, autonomia e liderança, ocupando lugar de destaque nas organizações.

\section{QUAIS SÃO AS CARACTERÍSTICAS DE UM EMPREENDEDOR?}

As características do empreendedor é um dos temas centrais nos estudos sobre empreendedorismo. Do empreendedor depende primariamente o sucesso ou o fracasso de um empreendimento. Neste sentido, a educação em empreendedorismo, seja nas Universidades ou em qualquer outro nível, envolve necessariamente um trabalho intenso quanto às características de um empreendedor, identificando-as, despertando-as e cultivando-as nos alunos.

$\mathrm{Na}$ literatura sobre empreendedorismo, várias definições de um empreendedor têm aparecido nos últimos séculos, tais como ${ }^{12}$ (i) uma pessoa auto-empregada (R. Canrillon/1730); (ii) um administrador, coordenador disposto a correr riscos (A. Nicollas/1767, J. B. Say/1810, F. Knight/1921 e J. E. Stepanek/1960); (iii) pessoa com necessidade de autonomia e realização (D. C. McClelland/ 1961, O. F. Collins/1964); (iv) pessoa com perseverança e um lócus de controle interno (R. L. Budner/1962, W.D. Lintzinger/1965, J.B. Rotter/1976), (v) pessoa com habilidade de arbitragem (I. Kirzner/ 1979); (vi) pessoa capaz de identificar oportunidades e desenvolver pequenos empreendimentos (E. Penrose/1959) e, (vii) um inovador criativo (J. Schumpeter/1910).

No entanto, uma definição de empreendedor que parece ser mais compreensiva é “ a pessoa que conduz o processo de criação de riqueza e de agregação de valor através do desenvolvimento de idéias, da obtenção e alocação de recursos e da realização de coisas - fazendo as coisas acontecerem"12.

De qualquer forma, todas estas definições trazem alguns elementos comuns que estão resumidos no Quadro $1^{17,18}$.

Existe uma certa tendência de se confundir o empreendedor com o admistrador/executivo. Embora complementares, existem algumas diferenças que merecem ser consideradas (Tabela 1), especialmente no momento de definir um modelo de educação a ser adotado.

Quadro 1. Algumas características de empreendedores de sucesso

- visionários, cultivam a imaginação e aprendem a definir visões;

- sabem tomar decisões;

- indivíduos que fazem a diferença;

- senso de oportunidade, explorar ao máximo as oportunidades;

- determinados e dinâmicos, perseverantes, tenazes para vencer obstáculos;

- dedicados e com alto comprometimento;

- otimistas e apaixonados pelo que fazem, sonhadores realistas que traduzem pensamentos em ação;

- independentes e constroem o próprio destino, iniciativa, autoconfiança, otimismo e necessidade de auto-realização;

- aceitam o dinheiro como medida de desempenho;

- são líderes e formadores de equipes;

- formam as redes de contatos e as utilizam intensamente para alcançar os objetivos;

- planejam, sabem fixar metas e alcançá-las;

- organizados, sabem buscar, controlar e utilizar recursos;

- possuem conhecimento (buscam o conhecimento), especialmente no ramo em que atuam. Procuram feedback para se aprimorarem;

- assumem riscos calculados e têm alta tolerância à incerteza;

- criam valor para a sociedade.

Tabela 1. Diferenças nos sistemas de atividades de administradores e empreendedores. Adaptada das refs. 19 e 20

Adminstrador/executivo Empreendedor

Trabalha no uso eficiente e efetivo de recursos para atingir

Define a visão, o objetivo e identifica recursos para realizá-la.

metas e objetivos.

Chave: adaptar-se às mudanças.

Chave: iniciar as mudanças.

Padrão de trabalho: implica em análise racional.

Opera dentro de um quadro existente.

Trabalho centrado em processos que levam em consideração

Padrão de trabalho: implica em imaginação e criatividade.

o ambiente externo.

Define tarefas e papéis que criam um novo quadro organizacional. Trabalho centrado na criação de novos processos baseados em uma visão diferenciada do ambiente.

Educação: indivíduo preparado para integrar uma cultura de subordinação, trabalho no grupo, trabalha os dois lados do cérebro com ênfase no lado esquerdo (racional), reflexão baseada na abstração e identificação de regras gerais.

Educação: indivíduo preparado para exercer liderança, progressão individual, trabalha os dois lados do cérebro com ênfase no lado direito (imaginação/criatividade), reflexão baseada na prática. 
De acordo com a teoria visionária de Filion $^{21-24}$, o empreendedor é uma pessoa que tem a capacidade de imaginar, desenvolver e realizar visões, onde os conceitos de si, energia, liderança, conhecimento de um setor e o sistema de relações do empreendedor são elementos fundamentais. Trabalhos de pesquisa com empreendedores de sucesso ${ }^{25}$ sugerem a existência de três recursos de conhecimento que um empreendedor traz para um novo negócio e que são críticos: a consciência única da oportunidade, a habilidade de adquirir os recursos necessários para explorar a oportunidade e a habilidade organizacional.

\section{EMPREENDEDOR: DOM OU EDUCAÇÃO?}

O senso comum considera que as características empreendedoras do ser humano são inatas, sendo que somente uma minoria nasceria com esse dom, enquanto uma maioria estaria destinada a se submeter às orientações e vontades de terceiros ${ }^{18}$. No entanto, como discutido a seguir e na opinião de Dolabela ${ }^{26}$ "o espírito empreendedor é um potencial de qualquer ser humano e necessita de algumas condições indispensáveis para se materializar e produzir efeitos".

Existe um debate se programas com o objetivo de "educar" pessoas a serem empreendedoras podem ter sucesso ou não. A questão principal neste contexto é se empreendedorismo é uma habilidade adquirida na juventude, em um ambiente familiar favorável e onde a cultura local encoraja a iniciativa e não a dependência, ou uma atitude, habilidade ou conjunto de conhecimentos/habilidades que podem ser ensinadas. Vários pesquisadores da linha comportamental/humano consideram que ambos, talento e educação, são importantes na formação de empreendedores.

Assim, várias experiências na área de educação empreendedora têm mostrado que empreendedores podem sim, ser feitos, embora isso não seja um processo simples, dependendo de um ambiente favorável e um mínimo de condições externas. Um estudo sobre empreendedorismo no Canadá ${ }^{27}$, mostra que no caso de empreendedores tecnológicos, existe uma situação especial, onde o empreendedor normalmente tem uma formação técnica/científica, por ex., em Química, Física ou Engenharia, antes da formação empreendedora. Este estudo sugere então que empreendedores tecnológicos podem sim ser "feitos" e aponta algumas das razões para isso, mostradas no Quadro 2:

Quadro 2. Características da formação de empreendedores tecnológicos

- a maioria dos empreendedores tecnológicos se iniciaram com
idade acima de 30 ou 40 anos, e tiveram que ser educados em
tecnologia e empreendedorismo/adminstração antes de se
estabelecerem como empreendedores;
- a educação baseada em ciência e tecnologia, como por ex.,
Química e Engenharia Química, abre uma vista completa-
mente nova e inspira jovens a começar seus próprios negócios;
- os elementos sonho, idealismo e desenvolvimento pessoal
estão presentes de forma intensa em empreendedores tecnoló-
gicos e não tanto por dinheiro;
mesmo para empreendedores com pais empresários, a
motivação para iniciar um novo negócio está baseada principal-
mente em outros fatores considerados mais importantes e,
- a educação empreendedora, principalmente nos setores de alta
tecnologia pode ser bem sucedida se for suficientemente
focada e concentrada.

Experiências desde 1993 na Universidade de Calgary, no Canadá e na Swinburne University of Technology, em Melbourne ${ }^{28,29}$ mostram que 35 até $87 \%$ dos graduados abrem uma empresa e que, no início das vendas, criam em média oito empregos diretos.

\section{O ENSINO DE EMPREEDEDORISMO NO BRASIL ${ }^{17,18,29}$}

A Tabela 2 mostra alguns eventos importantes conhecidos relacionados ao ensino de empreendedorismo no Brasil.

As primeiras iniciativas ocorreram em 1981 e 1984 através da criação de cursos de empreendedorismo isolados. Em termos de iniciativas institucionais vale citar a criação do CESAR na UFPE, em 1992 do GEFEI na EFEI e do GEPE na UFMG, em 1995, que vai ter um papel importante na definição da metodologia utilizada para o ensino de empreendedorismo no Brasil, através de um série de workshops realizados com pesquisadores canadenses ${ }^{17}$.

Para o ensino em nível nacional foi criada, em 1993, a primeira rede de ensino de empreendedorismo pelo programa SOFTEX do CNPq e, em 1997, a rede REUNE. Segundo dados da REUNE, já são mais de 200 IES no país que oferecem regularmente cursos de Empreendedorismo.

Tabela 2. Principais eventos relativos ao ensino de empreendedorismo no Brasil

Ano Atividades

1981 O ensino de empreendedorismo inicia-se no Brasil, na Escola de Administração de Empresas da Fundação Getúlio Vargas em São Paulo.

1984 USP oferece o ensino de empreendedorismo.

1984 É ministrado o primeiro curso de empreendedorismo em um Departamento de Ciência da Computação da UFRGS pelo Prof. Newton Braga Rosa.

1992 Departamento de Informática da UFPE criou o CESAR (Centro de Estudos e Sistemas Avançados do Recife), com objetivo de ser um núcleo de aproveitamento industrial dos resultados acadêmicos.

1993 Rede de ensino de empreendedorismo pelo programa SOFTEX/CNPq com o núcleo FUMSOFT/MG, desenvolvimento de uma metodologia de ensino de empreendedorismo, que se mostrou um grande sucesso, resultando no programa SOFTEX-SOFTSTART que atingiu mais de 100 departamentos de ensino de informática em 23 estados brasileiros e no Distrito Federal ${ }^{30}$.

1995 EFEI, Escola Federal de Engenharia de Itajubá (MG) criou o GEFEI (Centro Empresarial de Formação Empreendedora em Itajubá) com objetivo de promover o ensino de empreendedorismo na instituição.

1995 Criação do GEPE (Grupo de Estudos da Pequena Empresa) no Departamento de Engenharia de Produção da UFMG.

1997 Constituição da Rede de Ensino Universitário de Empreendedorismo (REUNE), programa instituído com apoio da Confederação Nacional da Indústria (CNI), Instituto Euvaldo Lodi (IEL), SEBRAE-MG, FUMSOFT, Secretaria do Estado de Ciência e Tecnologia de MG e Fundação João Pinheiro.

1999 Criado na UFSC o Programa Engenheiro Empreendedor, que oferece cursos na área de empreendedorismo e organiza concursos de planos de negócios para alunos das engenharia, inclusive engenharia química ${ }^{31}$. 
Outras iniciativas também muito interessantes que promovem a educação empreendedora, não só para o público acadêmico, mas para o público geral, são os programas EMPRETEC ${ }^{33}$ o programa Jovem Empreendedor do SEBRAE ${ }^{34}$ e o projeto "Empreendedorismo Para o Ensino Fundamental" promovido pelo SEBRAE-SP ${ }^{35}$.

\section{POR QUE O ENSINO DE EMPREENDEDORISMO PODE SER MUITO POSITIVO PARA A QUÍMICA?}

1- Porque a criação de empresas, seja ela de base tecnológica em Química ou de outra natureza, é uma possibilidade real para os nossos alunos e os demais químicos formados já atuantes no mercado. Nossos estudantes de química, sejam de graduação ou pós-graduação, nem sequer imaginam ou cogitam a possibilidade de realizarem algo diferente de encontrar um emprego em uma indústria, em órgão público ou lecionar em uma escola de ensino médio ou universidade. Além disso, uma grande massa de mão-de-obra com formação em química já existente no mercado de trabalho, com um enorme potencial, também não vislumbra esta possibilidade. A geração de empresas de base química contribui diretamente para ampliar o mercado de trabalho para químicos, gerar riquezas e empregos para a sociedade, contribuindo para o desenvolvimento tecnológico do país. Temos que formar alunos que acreditem em sua capacidade de protagonizar o desenvolvimento e a construção do futuro.

2- Empreendedorismo Tecnológico é de grande importância. Profissionais com formação em ciências, tais como químicos, bió$\operatorname{logos}$, físicos e engenheiros estão em uma posição única para atuar no processo de inovação tecnológica, que é um elemento chave para aumentar a competitividade em uma economia global que evolui rapidamente. Somos capazes de desenvolver produtos e serviços com alto valor agregado e fazer um uso completo dos recursos humanos disponíveis na área de ciência e tecnologia no Brasil. A necessidade de firmas inovadoras é de suma importância, visto que são a fonte principal de novos empregos e riqueza em nossa sociedade moderna.

3- Porque o ensino de empreendedorismo forma não só o "entrepreneurs" mas também os "intrapreneurs" ou intra-empreendedores. O intra-empreendedor é o indivíduo que é empregado de uma organização, seja privada ou pública, e que tendo as características de um empreendedor, normalmente desempenha papéis chaves, de liderança e/ou de tomada de decisão. Empregados com atitudes empreendedoras são capazes de perceber diferentes oportunidades, encontrar recursos e introduzir inovações em sua organização. Assim, a educação empreendedora deve contribuir para a formação de profissionais muito mais atuantes no mercado de trabalho.

4- Porque o empreendedorismo pode contribuir para uma valorização da Química, como ciência e como profissão. A Química é uma ciência central de importância capital em nossa sociedade. No entanto, uma ciência que atualmente é vista negativamente em alguns aspectos e pouco valorizada no mercado de trabalho. Empreendedores são agentes de mudança, capazes de transformar o enorme conhecimento químico em tecnologia, em resultados mais palpáveis, levando à realização pessoal e profissional. Indivíduos empreendedores são capazes de dinamizar suas comunidades, desenvolvendo suas potencialidades e certamente contribuindo para uma mudança de imagem.

\section{COMO O EMPREENDEDORISMO PODE SER ENSINADO} NOS CURSOS DE QUÍMICA?

A "Harvard Business School” foi a primeira a introduzir um cur- so em empreendedorismo em 1947, mas até 1970 poucas universidades americanas ofereciam cursos nesta área. A partir de 1970 houve um grande aumento no número destes cursos nos EUA, chegando a mais de 400 de acordo com um levantamento feito em $1995^{36}$. Embora a maior parte destes cursos seja normalmente oferecida em faculdades de administração, um grande número passa a ser oferecido também em faculdades e departamentos de ciências e engenharias. Um levantamento no ano de 2004 sobre educação em empreendedorismo no Canadá ${ }^{37}$ mostrou que dos 243 cursos em empreendedorismo oferecidos para alunos de graduação em todo o país, 45 eram voltados para o empreendedorismo tecnológico, sendo que 19 são oferecidos em faculdades de engenharia e 10 em outros departamentos ou faculdades tais como medicina, enfermagem, agronomia, ciências ambientais, matemática e computação (Esquema 3).

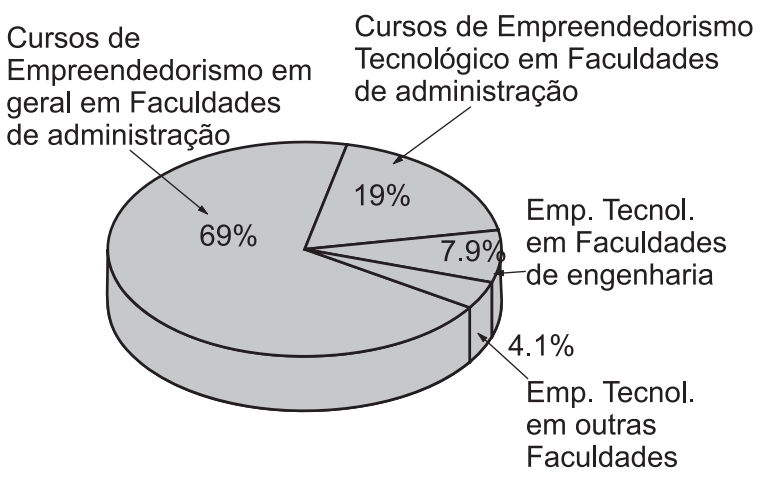

Esquema 3

Neste estudo, é reconhecida a necessidade de se implementar cursos de empreendedorismo para uma maior gama de estudantes de diferentes áreas, especialmente para áreas com potencial de criação de empresas de base de alta-tecnologia. Fica muito clara a tendência do ensino de empreendedorismo permear todos os ambientes acadêmicos.

Cursos de empreendedorismo em universidade canadenses, americanas e artigos em educação em empreendedorismo ${ }^{27}$ mostram alguns elementos comuns que podem ser identificados em cursos de empreendedorismo, por ex. o trabalho do lado comportamental, a análise de oportunidades, preparo de um plano de negócios, palestra de empreendedores convidados, leituras e estudos de caso $^{38}$.

No entanto, um curso de empreendedorismo deve ser personalizado, levando em conta o público alvo (origem, formação, idade), o tempo disponível e o objetivo do curso. Nas palavras de Filion ${ }^{39}$ um curso de empreendedorismo deve preparar o participante nos seguintes moldes: "Ser um empreendedor envolve o pensar e o agir de uma forma baseada na imaginação e na diferenciação. Empreendedores utilizam o lado direito do cérebro - intuição, imaginação e criatividade - bem como o lado esquerdo - racionalidade, análise e julgamento. O fundamento da prática empreendedora é a habilidade de identificar oportunidades de negócio e então estruturar visões de ações futuras. Isto significa estar apto a pensar individualmente e também ser apto a compartilhar a visão com outros. $O$ sucesso de um projeto empreendedor depende não apenas da habilidade de focar em um objetivo, mas também da habilidade de envolver outras pessoas no processo visionário”.

A partir de uma análise preliminar dos programas dos cursos em empreendedorismo oferecidos para cursos de graduação nas áreas de ciências e engenharias, sugere-se na Tabela 3 a estrutura de um curso de empreendedorismo especificamente para a área de Química. Este curso é dividido em quatro partes e pode ser oferecido para alunos e também para professores. 
Tabela 3. Estrutura de um curso de empreendedorismo para a área de Química

\begin{tabular}{|c|c|c|}
\hline Parte & Objetivos & Atividades \\
\hline $\begin{array}{l}\text { Parte } 1 \\
\text { Emprendedor } \\
\text { é dirigida à figura do } \\
\text { empreendedor, o } \\
\text { pensamento empreendedor, } \\
\text { a descoberta das } \\
\text { características e métodos de } \\
\text { um empreendedor. }\end{array}$ & $\begin{array}{l}\text { - exame e identificação do próprio } \\
\text { potencial empreendedor; } \\
\text { - Aprendizado sobre: } \\
\text { - os principais caminhos de } \\
\text { empreendedores, } \\
\text { - o pensar em termos } \\
\text { empreendedores e, } \\
\text { - o cultivo do pensamento e ação } \\
\text { empreendedora }{ }^{35} \text {. }\end{array}$ & $\begin{array}{l}\text { - } \text { análise de textos e atividades de discussão; } \\
\text { - } \text { eminários de empreendedores, entrevistas com } \\
\text { - utilizar estudos de caso, com (i) químicos ao longo da } \\
\text { história no Brasil e no mundo, (ii) químicos } \\
\text { contemporâneos que criaram empresas de sucessos e, (iii) } \\
\text { acadêmicos brasileiros na área de ciências que criaram } \\
\text { empresas "spin-off" a partir de resultados de pesquisa.; } \\
\text { - mostrar as motivações, as características pessoais do } \\
\text { empreendedor, as principais dificuldades, os sacrifícios e } \\
\text { os benefícios da vida empreendedora e, } \\
\text { - "brainstorming" e reflexão, estimulando os participantes } \\
\text { do curso a utilizar suas experiências e seus potenciais para } \\
\text { desenvolver a capacidade de encontrar soluções e } \\
\text { respostas de forma autônoma e criativa. }\end{array}$ \\
\hline
\end{tabular}

\section{Parte 2}

Análise Setorial

Análise específica do setor químico, assumindo que os participantes do curso têm interesse neste setor.
- investigar e discutir as atividades industriais químicas no Brasil e no exterior;

- fazer uma apreciação dos diferentes setores e,

- avaliar cenários futuros, identificando e discutindo oportunidades.
Embora uma análise detalhada do setor químico seja impossível dentro do escopo do curso, espera-se que esta atividade exercite os participantes na análise de oportunidades e no desenvolvimento das habilidades:

- adquirir e desenvolver o método de pensamento empreendedor;

- aprender a analisar e decodificar o setor de química;

- estabelecer ligações entre necessidades de mercado e habilidade em satisfazer essas necessidades;

- familiarizar-se com o mundo dos negócios;

- aprender a identificar oportunidades de negócio e,

- iniciar um plano de negócios.

\section{Parte 3}

Plano de negócios e plano tecnológico são

apresentados aos participantes do curso.
Apresentar ao participante o PN, que é ferramenta fundamental para iniciar um negócio e que permite mapear o caminho a ser seguido.
- Aprendizado das etapas no preparo de um PN;

- utilização do PN para melhor avaliação da oportunidade;

- identificar as principais forças, fraquezas, oportunidades e ameaças relacionadas com o negócio que se pretende empreender e,

- familiarizar-se com EVTE para a avaliação de aspectos técnicos, econômicos, de mercado e de marketing.

Discussão dos temas:

- fontes de financiamentos (economia pessoal/familiar, "Angel investors", capital de risco, fontes governamentais, etc);

- patentes e contratos de confidencialidade;

- assessoria jurídica e contábil e,

- incubadoras, centros de empreendedorismo, organizações tais como o SEBRAE, Endeavor, etc.
Vale enfatizar que este é um curso de empreendedorismo tecnológico que possui conteúdo químico, por ex., análise do Setor Químico, Produtos Químicos, Cadeias Produtivas, etc. Uma outra opção para o ensino de empreendedorismo é sua inserção em um curso com conteúdo químico. Um exemplo que pode ser utilizado aqui é uma disciplina optativa chamada "Transformação de Rejeitos em Materiais de Importância Tecnológica" oferecida aos alunos de química da UFMG (60 h, 4 créditos). Esta disciplina foi dividida em módulos, que são resumidos na Tabela 4.

$\mathrm{Na}$ atividade proposta no Módulo 3, após escolher o rejeito e o processo, os alunos irão fazer as primeiras considerações sobre:

(i) planta necessária para a operação (área, maquinário, instalações, funcionários, etc); (ii) elementos de logística (como garantir o fornecimento do rejeito, onde vender o produto) e,

(iii)o capital necessário para iniciar e operar o negócio e as expectativas de retorno.

Embora de uma forma ainda muito rudimentar, devido às limitações de tempo e de conhecimento, os alunos têm em mãos elementos para já prepararem um primeiro plano de negócios. No caso desta disciplina, este primeiro plano de negócios foi preparado e apresentado na incubadora de empresas da UFMG para um grupo de avaliadores composto por empresários, o gerente da incubadora, engenheiro com experiência na construção de plantas industriais, industriais, entre outros. Esta apresentação é muito importante, pois expõe os alunos a uma situação que eles certamente encon- 
Tabela 4. Estrutura do curso “Transformando Rejeitos em Materiais de Importância Tecnológica” com conteúdo em empreendedorismo

\begin{tabular}{|c|c|c|}
\hline Módulos & Objetivos & Exemplo \\
\hline $\begin{array}{l}\text {-1: Discussão dos principais rejeitos } \\
\text { gerados em nossa sociedade. }\end{array}$ & $\begin{array}{l}\text { Conhecer os principais rejeitos, abordando } \\
\text { aspectos industriais, ambientais e } \\
\text { econômicos relativos à geração e reciclagem } \\
\text { destes rejeitos. }\end{array}$ & $\begin{array}{l}\text { Rejeitos de origem polimérica, metálica, } \\
\text { mineral, vegetal, etc. }\end{array}$ \\
\hline $\begin{array}{l}\text {-2: Discussão dos processo de } \\
\text { reciclagem de alguns rejeitos. }\end{array}$ & $\begin{array}{l}\text { Selecionar alguns rejeitos e avaliar aspectos } \\
\text { técnicos, econômicos e de logística } \\
\text { envolvidos na cadeia de reciclagem. }\end{array}$ & $\begin{array}{l}\text { Reciclagem de alguns rejeitos com processos } \\
\text { mais definidos e conhecidos, e.g. PET, } \\
\text { alumínio, vidro e processos de reciclagem } \\
\text { menos estabelecidos. }\end{array}$ \\
\hline $\begin{array}{l}\text {-3: Escolha pelos grupos de alunos } \\
\text { ( } 5 \text { alunos por grupo) de um rejeito } \\
\text { específico. }\end{array}$ & $\begin{array}{l}\text { Considerar um processo específico de } \\
\text { reciclagem (conhecido ou completamente } \\
\text { novo) para produzir um produto específico } \\
\text { - Plano Tecnológico. }\end{array}$ & $\begin{array}{l}\text { por ex. catalisadores usados de carro para } \\
\text { recuperação de metais nobres através de } \\
\text { lixiviação, reciclagem de pilhas para } \\
\text { recuperação de zinco e ferro metálico, grafite } \\
\text { e carvão. }\end{array}$ \\
\hline
\end{tabular}

trarão como empreendedores e permite um contato com pessoas chave da área de empreendedorismo que darão um "feedback" precioso para o aprendizado empreendedor.

Nesta disciplina, o tema empreendedorismo não foi abordado de forma direta, mas o ambiente empreendedor foi criado e a atitude empreendedora foi cultivada dentro da sala de aula. O resultado foi um grupo de alunos extremamente motivados que, no decorrer do curso, despertaram um sonho, criaram uma visão de um negócio e iniciaram a organização dos elementos necessários para concretizar a visão e o sonho. Como mencionado por Dolabela " $A$ novidade está em dominarmos formas de incorporar ao processo de aprendizado elementos como a emoção, o conceito de si, a criatividade, o não-conformismo e a persistência" ${ }^{17}$.

Disciplinas na área de empreendedorismo são capazes de transformar os participantes, criando alunos mais pró-ativos, com mais energia e entusiasmo, o que deve levar a um melhor desempenho em outras disciplinas do curso de Química.

Um outro aspecto muito importante na criação de cursos de empreendedorismo é que serão necessários professores capacitados para formação de empreendedores. De preferência existirão professores "empreendedores", que são exemplos vivos e muito importantes para os alunos. Uma interação com os professores e pesquisadores de faculdades de administração e economia, e com escolas técnicas de administração pode ser também realizada, sendo isso muito positivo para ambas as comunidades. Outra atividade muito interessante para nossos alunos de graduação são as Empresas Juniores que, como atividade empreendedora, dão oportunidade única para nossos alunos de atuarem como consultores, conhecerem o mercado e amadurecerem como profissionais. Além disso, no processo empreendedor dentro da Universidade normalmente se estabelece uma forte interação com Centros de Empreendedorismo, Incubadoras, Parques Tecnológicos e empresas criadas para aceleração de tecnologias. Uma destas empresas aceleradora de tecnologia é o Instituto Inovação, que pode ser conhecido em maiores detalhes no website www.institutoinovacao.com.br.

\section{SUGESTÕES DE LEITURA}

A área de ensino de empreendedorismo já conta com várias publicações no Brasil e, embora de forma não exaustiva, algumas publicações são sugeridas no Quadro 3. Os livros de Fernando Dolabela sem dúvida merecem uma menção especial pela clareza e paixão com que o autor escreve e pelos caminhos que nos aponta.
Quadro 3. Sugestão de leitura na área de empreendedorismo

- "Oficina do Empreendedor" de Dolabela, ref. 17, apresenta uma metodologia para o ensino de empreendedorismo com uma série de exercícios, sugestões e programas de cursos.

- "Pedagogia Empreendedora", ref. 26, que trata do ensino de empreendedorismo na educação básica voltado para o desenvolvimento social sustentável.

- "O Segredo de Luísa", de Dolabela é um romance que narra a estória de Luísa que quer montar uma empresa, mas não sabe por onde começar. Um amigo então passa a lhe ensinar muitas coisas sobre administração, até que ela consegue montar uma fábrica de goiabada. Através deste romance Dolabela dá ao leitor muitas lições de empreendedorismo.

- "Boa Idéia! E agora? Plano de Negócio, o caminho mais seguro para criar e gerenciar sua empresa." de Dolabela e Filion (Ed. Cultura, São Paulo, 2000), coletânea coordenada por Louis Jacques Filion e Fernando Dolabela.

- "Empreendedorismo: Transformando Idéias em Negócios", Ref. 18, muito interessante e mostra vários aspectos do processo empreendedor, entre eles a identificação de oportunidades, plano de negócios e dicas de busca de financiamento e assessoria.

- "Tchau Patrão" (Ed. SENAC-MG, 2003), de Eder Luiz Bolson, é dirigido para aqueles que querem iniciar seu próprio negócio.

- O SEBRAE oferece um curso gratuito por Internet chamado "Iniciando um Pequeno Grande Negócio" onde se aborda o perfil do empreendedor, identificação de oportunidades, análise de mercado, concorrentes, fornecedores, análise financeira, etc.

Alguns sites interessantes para visitar são:

www.sebrae.org.br,

www.endeavour.org.br,

www.gemconsortium.org,

www.planodenegocios.com.br,

www.empresario.com.br,

www.geranegocios.com.br,

www.entrepreneurship.com.br,

www.entreworld.org,

www.dolabela.com.br,

www.businessplan.org,

www.empreendedor.com.br,

www.empresario.com.br 


\section{CONCLUSÃO}

Como cotado no livro de Dornelas, a citação de Jeffry Timmons ${ }^{40}$ é enfática: "O empreendedorismo é uma revolução silenciosa, que será para o século XXI mais do que a revolução industrial foi para o século XX'. Esta revolução está dentro das Universidades também. De acordo com Filion ${ }^{41}$, a lógica pela qual as universidades funcionam tem mudado e vai mudar nos próximos séculos de acordo com:

- a lógica de ensino entre 1200-1950;

- a lógica de pesquisa entre 1800-2050;

- a lógica da contribuição social 1960-2060;

- a lógica do empreendedorismo 2000-2080 e,

- a lógica ecológica (sustentabilidade) 2020-3000.

A Universidade certamente tem um papel duplo muito importante na lógica da contribuição social e na lógica do empreendedorismo: ela pode contribuir para formação do empreendedor e da cultura empreendedora em nossa sociedade e nas universidades serão desenvolvidas pesquisas e conhecimentos que gerarão novas empresas de base tecnológica importantes para nossa sociedade. Nós acadêmicos, professores ou estudantes, também devemos ter uma atitude empreendedora e sermos agentes pró-ativos neste processo de transformação que nossas Universidades estão passando neste início de século XXI e vão passar nas próximas décadas.

\section{AGRADECIMENTOS}

À FAPEMIG, ao CNPq, à CAPES, à UFMG e HEC.

\section{REFERÊNCIAS}

1. Etzkowitz, H.; Webster, A.; Gebhardt, C.; Res. Policy 2000, 29, 313

2. Blumenthal, D.; Science 1986, 231, 242.

3. Blumenthal, D.; Science 1986, 232, 1361.

4. Krimsky; S.; Sci. Techn. Human Values 1991, 16, 275.

5. http://www.fapesp.br, acessada em Maio 2005. Indicadores de Ciência e Tecnologia de São Paulo 2004, Publicação FAPESP, 2005.

6. http://www.fapesp.br, acessada em Maio 2005. Programa Inovações Tecnológicas em Pequenas Empresas (PIPE), Programa Novas Fronteiras - Propriedade intelectual.

7. http://www.mct.gov.br, acessada em Maio 2005. MCT, Fundo Verde Amarelo (Universidade-Empresa).

8. de Andrade, J. B.; Cadore, S.; Vieira, P. C.; Zucco, C.; Pinto, A. C.; Qiím. Nova 2003, 26, 445.

9. de Andrade, J. B.; Cadore, S.; Vieira, P. C.; Zucco, C.; Pinto, A. C.; Quim. Nova 2004, 27, 358.
10. Hindle, K.; Yecken, J.; Technovation 2004, 24, 793.

11. Uma lista completa dos periódicos, inclusive os sem referagem, pode ser encontrada em (http://eweb.slu.edu/booklist.htm, acessada em Maio 2005.

12. Kao, R. W. Y.; Kao, K. R.; Kao, R. R. Entrepreneurism, Imperial College Press: London, 2002, p. 29.

13. http://www.sebrae.br, acessada em Maio 2005.

14. http://www.endeavour.org.br, acessada em Maio 2005.

15. http://www.gemconsortium.org, acessada em Maio 2005. Entrepreneurship Monitor 2003

16. http://www.mec.gov.br, acessada em Maio 2005.

17. Dolabela, F.; Oficina do Empreendedor, $6^{\mathrm{a}}$ ed., Ed. de Cultura: São Paulo, 1999.

18. Dornelas, J. C. A.; Empreendedorismo: Transformando Idéias em Negócios, Elsevier: São Paulo, 2001.

19. Filion, L. J.; Revista de Administração de Empresas FGV 2000, 7, 2

20. Filion, L. J.; HEC Cahier de Recherche 1994, 94-02-01.

21. Filion, L. J.; Revista de Administração de Empresas FGV 1993, 33, 50.

22. Filion, L. J.; Revista de Administração de Empresas FGV 1991, 31, 63.

23. Filion, L. J.; Revista de Administração de Empresas FGV 1999, 39, 6.

24. Filion, L. J.; RAUSP Revista de Administraçao 1999, 34, 5.

25. Alvarez, S. A.; Busenitz, L. W.; J. Manag. 2001, 27, 755.

26. Dolabela, F.; Pedagogia Empreendedora, Ed. de Cultura: São Paulo, 2003.

27. Blais, R. A.; Doyle, D. J.; Gilsig, T.; Heffernan, G.D.; Lamarre, B.; Lyrette, B.; Maher, P. M.; Paradi, J. C.; Technological Entrepreneurship in Canada, The Canadian Academy of Engineering Press: Ottawa, 1997.

28. McMullan, E. W.; Trans. Babson College Entrepreneurship Conference, University of Washington, Seattle, EUA, 1996.

29. Mcmullan, W. E.; Gellin, L. M.; Technovation 1998, 18, 275.

30. Rocha, J. G. C.; Filho, E. C. B. C.; "Universidade Federal de Pernambuco Empreendedora",http://www.desenvolvimento.gov.br/arquivo/sti/ publicacoes/futAmaDilOportunidades/rev20020325_05.pdf, acessada em Maio 2005.

31. http://www.softex.br, acessada em Maio 2005

32. http://www.ctc.ufsc.br/empreendedor, acessada em Maio 2005.

33. http://www.df.sebrae.com.br/preview/creator2/webs/sebrae/cursoseventos/ empretec, acessada em Maio 2005.

34. http://www.sebrae.com.br/br/programaseprojetos/ programaseprojetos_1945.asp, acessada em Maio 2005.

35. http://www.empresario.com.br/futuro/futuro_txt/brincando.html acessada em Maio 2005

36. Katz, J. A.; J. Bus. Venturing 2003, 18, 283.

37. Menzies, T. V.; Entrepreneurship and the Canadian Universities. Report of a National Study of Entrepreneurship Education:2004, Brock University Press: Ontário, 2004, disponível em http://eagle.bus.brocku.ca/ tmenzies/

38. Gartner, W. B.; Vesper, K. H.; J. Bus. Venturing 1997, 12, 403.

39. Filion, L. J.;Curso MBA "Visionary and Entrepreneurial Thinking", HEC, Montreal, 2005.

40. Timmons, J .A.; Spinelli, S.; New Venture Creation Enterprise for the $21^{\text {st }}$ Century, 6 ${ }^{\mathrm{a}}$ ed., McGraw Hill: Nova Iorque, 2004.

41. Filion, L. J.; comunicação pessoal. 